\title{
Pancreatic Safety of Once-Weekly Dulaglutide in Chinese Patients with Type 2 Diabetes Mellitus: Subgroup Analysis by Potential Influencing Factors
}

\author{
Yan Zhou · Jiankun Zhu · Haiya Wu · Yuying Deng • Qiuhe Ji (D)
}

Received: April 30, 2021 / Accepted: August 4, 2021 / Published online: August 28, 2021

(c) The Author(s) 2021

\begin{abstract}
Introduction: In the randomized, open-label, parallel-arm, active-controlled phase III AWARD-CHN2 trial, once-weekly dulaglutide plus concomitant oral antihyperglycemic medications (OAMs) improved HbA1c over 26 weeks compared with once-daily insulin glargine in patients with type 2 diabetes mellitus (T2DM). This post-hoc subgroup analysis of AWARDCHN2 investigated the pancreatic safety of dulaglutide in Chinese patients with T2DM, stratified by potential influencing factors.

Methods: Changes in pancreatic enzyme (pancreatic amylase, total amylase, and lipase) levels
\end{abstract}

Supplementary Information The online version contains supplementary material available at https:// doi.org/10.1007/s13300-021-01139-2.

Y. Zhou

Endocrinology Department of Xi'an International Medical Center Hospital, 777 Xitai Road, Gaoxin District, Xi'an 710100, Shaanxi Province, China

J. Zhu $\cdot$ H. Wu $\cdot$ Y. Deng $(\bowtie)$

Lilly Suzhou Pharmaceutical Co. Ltd., 19F, Centre T1, HKRI Taikoo, No. 288, Shimen No.1 Road, Jing'an District, Shanghai 200041, China e-mail: deng_yu_ying@lilly.com

Q. Ji ( $\square)$

Endocrinology Department of the First Affiliated Hospital (Xijing Hospital) of Air Force Medical University, 127 Changle West Road, Xincheng District, Xi'an 710032, Shaanxi Province, China e-mail: qiuheji@hotmail.com over 26 weeks were assessed and stratified by patient age $(<60, \geq 60$ years), sex (female, male), duration of diabetes $(<10, \geq 10$ years), baseline weight $(<70, \geq 70 \mathrm{~kg})$, BMI $(<25$, $\left.\geq 25 \mathrm{~kg} / \mathrm{m}^{2}\right)$, HbA1c $(<8.5, \geq 8.5 \%)$, triglycerides $(<2.3, \geq 2.3 \mathrm{mmol} / \mathrm{L})$, and concomitant OAMs (metformin, sulfonylurea, metformin plus sulfonylurea).

Results: A total of 203 Chinese patients with T2DM were included in this post-hoc analysis. Pancreatic enzyme levels increased within the normal range from baseline to Week 26 , and no pancreatitis events were confirmed by independent adjudication. Least-squares mean increase in pancreatic amylase (U/L) from baseline to Week 26 was comparable across all subgroups with no statistically (all P-values $>0.05$ ) or clinically significant betweengroup differences for age $(<60$ years: $5.34 ; \geq 60$ years: 6.71 ), sex (female: 5.85 ; male: 5.66), duration of diabetes $(<10$ years: 6.15 ; $\geq 10$ years: 4.85$)$, weight $(<70 \mathrm{~kg}$ : $6.19 ; \geq 70 \mathrm{~kg}: \quad 5.39), \quad$ BMI $\quad\left(<25 \mathrm{~kg} / \mathrm{m}^{2}\right.$ : $\left.5.92 ; \geq 25 \mathrm{~kg} / \mathrm{m}^{2}: \quad 5.61\right), \quad \mathrm{HbA} 1 \mathrm{c} \quad(<8.5 \%$ : $6.82 ; \geq 8.5 \%: 4.08)$, triglycerides $(<2.3 \mathrm{mmol} /$ L: $4.94 ; \geq 2.3 \mathrm{mmol} / \mathrm{L}: 8.04)$, and concomitant OAMs (metformin: 5.68; sulfonylurea: 5.44; metformin plus sulfonylurea: 5.87). Similar results were observed for total amylase and lipase.

Conclusion: In Chinese patients with T2DM receiving dulaglutide $1.5 \mathrm{mg}$ in AWARD-CHN2, elevations of pancreatic enzymes over 26 weeks 
were within the normal range and were neither associated with pancreatitis nor baseline factors, which suggests the clinical use of dulaglutide in Chinese patients with T2DM is not associated with pancreatic safety issues.

Clinical Trial registration: NCT01648582.

Keywords: Chinese patient; Dulaglutide; Pancreatic safety; Subgroup analysis; Type 2 diabetes

\section{Key Summary Points}

\section{Why carry out this study?}

Glucagon-like peptide-1 receptor agonists (GLP-1 RAs) are effective and safe for the treatment of type 2 diabetes (T2DM) but have been controversially linked to a possible increased risk of acute pancreatitis

This study evaluated the pancreatic safety of dulaglutide $1.5 \mathrm{mg}$, a GLP-1 RA, stratified by potential influencing factors, in Chinese patients with T2DM included in the phase III AWARD-CHN2 study

\section{What was learned from the study?}

In Chinese patients with type 2 diabetes receiving dulaglutide $1.5 \mathrm{mg}$, elevations of pancreatic enzymes (pancreatic amylase, total amylase, and lipase) over 26 weeks were within the normal range and were associated with neither pancreatitis nor baseline factors (patient age, sex, duration of diabetes, bodyweight, BMI, HbA1c, triglyceride level, or use of concomitant oral antihyperglycemic medications)

The clinical use of dulaglutide in Chinese patients with type 2 diabetes is not associated with pancreatic safety issues

\section{INTRODUCTION}

Type 2 diabetes (T2DM) is a progressive condition characterized by insulin resistance and progressive loss of $\beta$-cell function, which results in chronic hyperglycemia [1]. The prevalence of diabetes in China is increasing year by year and is estimated to be $12.8 \%$ based on the latest epidemiological survey conducted in China [2].

Glucagon-like peptide-1 receptor agonists (GLP-1 RAs) provide an effective treatment option for patients with T2DM with a relatively low risk of hypoglycemia and can also reduce bodyweight [3] However, there has been some controversy around a possible association between GLP-1 RAs and acute pancreatitis since cases of pancreatitis were observed in patients treated with exenatide in 2006 [4] Two subsequent studies conducted in the USA, a crosssectional database study [5] and a population based case-control study [6], reported an increased risk of pancreatitis and hospitalization for acute pancreatitis, respectively, in adults with T2DM receiving the GLP-1 RAs sitagliptin and exenatide. In contrast, several more-recent reviews of clinical trial evidence have found no increased risk of pancreatitis associated with GLP-1 RAs; a 2017 review of GLP-1 RA clinical trials [7] and a 2019 metaanalysis of seven GLP-1 RA cardiovascular outcome trials both found no increased risk of pancreatitis for patients receiving GLP-1 RAs versus placebo [8]. Following a comprehensive review of data for incretin-based therapies, the US Food and Drug Administration (FDA) and the European Medicines Agency (EMA) concluded that the available evidence does not support concerns about pancreatic safety for this class of drugs [9].

Dulaglutide is a GLP-1 RA approved in the EU, USA and China as a treatment for patients with T2DM [10]. The approval of dulaglutide in T2DM was supported by a series of Phase III trials under the AWARD (Assessment of Weekly AdministRation of LY2189265 [dulaglutide] in Diabetes) programme [10]. Collectively, these trials showed that dulaglutide, either as monotherapy or combined with other oral antihyperglycemic medication(s) (OAM), as well as 
insulin, was effective and generally well tolerated [10]. The randomized, Phase III AWARDCHN2 trial compared the efficacy and safety of once-weekly dulaglutide versus daily insulin glargine in a predominantly Asian population of patients with T2DM inadequately controlled with metformin and/or a sulphonylurea [11]. The primary results showed that once-weekly dulaglutide, 1.5 or $0.75 \mathrm{mg}$, provided significantly greater improvements in HbA1c over 26 weeks of treatment, with weight loss versus weight gain and less hypoglycemia, compared with once-daily insulin glargine [11]. Safety data from AWARD-CHN2 revealed small elevations in pancreatic enzyme levels within the normal range over time, with no confirmed cases of pancreatitis [11].

The etiology of acute pancreatitis is multifactorial and the most common risk factors include gallstones, alcohol use, hypertriglyceridemia and obesity [12-17]. Older individuals typically experience a higher incidence of gallstone-related acute pancreatitis due to abated functional reserves in organ systems [18, 19]. In addition, T2DM is associated with an increased risk of acute pancreatitis [20, 21]. However, the use of OAMs has been found to reduce pancreatitis risk, with a positive association reported between risk reduction and both the number of OAMs used and duration of OAM treatment [21] Therefore, patient age, bodyweight, body mass index (BMI), triglyceride levels, and use of concomitant OAMs are considered potential influencing factors for pancreatic safety in patients with T2DM. Given the high prevalence of T2DM among elderly Chinese people [22] and the preferential use of GLP-1 RAs in overweight and obese patients, due to their promotion of weight loss [23], it is particularly important to thoroughly investigate pancreatic safety in these patient subgroups.

Biomarkers of pancreatic inflammation including levels of pancreatic amylase, total amylase and lipase are routinely measured as part of a diagnosis of pancreatitis in clinical practice [13]. These biomarkers were also measured in several China registration trials of GLP1 RAs including dulaglutide $[24,25]$ and lixisenatide [26]. However, to date there has been no investigation of the pancreatic safety of GLP-1
RAs in a Chinese patient population stratified by the aforementioned potential influencing factors. This post-hoc subgroup analysis aimed to evaluate the pancreatic safety of dulaglutide $1.5 \mathrm{mg}$ in Chinese patients included in the AWARD-CHN2 study stratified by potential influencing factors. This represents the first such analysis of pancreatic safety stratified by potential influencing factors in Chinese patients with T2DM treated with GLP-1 RAs.

\section{METHODS}

\section{Study Design}

This was a post-hoc subgroup analysis of the AWARD-CHN2 study. The study design and patient eligibility criteria of AWARD-CHN2 (NCT01648582) have been published previously [11]. In brief, AWARD-CHN2 was an open-label (blinded to dulaglutide dose), randomized, noninferiority study that compared the efficacy and safety of once-weekly dulaglutide $1.5 \mathrm{mg}$ or $0.75 \mathrm{mg}$ versus once-daily insulin glargine in patients with T2DM [11]. The study was conducted at 45 sites in China, Russia, Mexico and South Korea between August 2012 and December 2014 [27]. Patients randomly assigned to dulaglutide $1.5 \mathrm{mg}$ received a fixed, doubleblind dose by subcutaneous injection once weekly and continued with their usual dose and regimen of OAM (metformin and/or a sulphonylurea). The primary efficacy endpoint was change in HbA1c from baseline to Week 26. The study protocol received approval from the ethics review board at each study center including the master ethics review board at Ruijin Hospital Affiliated to Shanghai Jiao Tong University. The study was conducted in-line with the ethical principles outlined in the Declaration of Helsinki and local regulations, and all patients provided written informed consent before randomization.

\section{Study Population}

AWARD-CHN2 included 774 adult patients ( $\geq 18$ years, 607 Chinese patients) diagnosed 
with T2DM for $\geq 6$ months based on the World Health Organization's diagnostic and classification criteria, with a BMI $\geq 19.0$ and $\leq 35.0 \mathrm{~kg} /$ $\mathrm{m}^{2}$, and $\mathrm{HbA} 1 \mathrm{c} \geq 53.0$ and $\leq 96.7 \mathrm{mmol} / \mathrm{mol}$ ( $\geq 7.0$ to $\leq 11.0 \%$ ) [11]. Eligible patients were also required to have been receiving metformin and/or a sulphonylurea for at least 3 months and been on a stable therapeutic dose for at least 8 weeks before screening. Key exclusion criteria included patients with type 1 diabetes, a clinically significant gastric emptying abnormality, clinical signs or symptoms of pancreatitis, a history of chronic pancreatitis or acute pancreatitis at visit 1 , serum amylase concentration $\geq 3$ times the upper limit of normal (ULN) and/or a serum lipase concentration $\geq 2$ times the ULN at visit 1 , serum calcitonin concentration $\geq 20 \mathrm{ng} / \mathrm{L}(5.83 \mathrm{pmol} / \mathrm{L})$, and receipt of insulin or a GLP-1 RA within 3 months before screening. The present post-hoc analysis included all Chinese patients in the safety population of the AWARD-CHN2 study who received at least one dose of dulaglutide $1.5 \mathrm{mg}$.

\section{Measurements}

This post-hoc subgroup analysis evaluated pancreatic safety in patients receiving dulaglutide $1.5 \mathrm{mg}$ by assessing least-squares (LS) mean change in pancreatic enzyme levels (pancreatic amylase, total amylase, and lipase) from baseline to Week 26, stratified by potential influencing factors. The potential influencing factors included in the analysis were: patient age $(<60$ or $\geq 60$ years), sex (male or female), duration of diabetes ( $<10$ or $\geq 10$ years), baseline weight $(<70$ or $\geq 70 \mathrm{~kg})$, baseline BMI $(<25$ or $\left.\geq 25 \mathrm{~kg} / \mathrm{m}^{2}\right)$, baseline HbA1c $(<8.5$ or $\geq 8.5 \%)$, baseline triglycerides $(<2.3$ or $\geq 2.3 \mathrm{mmol} / \mathrm{L}$; selected based on the National Cholesterol Education Program [NCEP] Adult Treatment Panel III [ATP III] criteria [28]), and concomitant OAMs (metformin only, sulfonylurea only, or metformin plus sulfonylurea).

Potential instances of pancreatitis were adjudicated by the Duke Clinical Research Institute Clinical Event Classification Group, which is an independent committee external to Eli Lilly and Company consisting of expert physicians. Two of the following three criteria were required for an event to be adjudicated as confirmed acute pancreatitis: (1) abdominal pain, characteristic of acute pancreatitis; (2) serum amylase and/or lipase level $\geq 3$ times the ULN; (3) characteristic findings of acute pancreatitis on computed tomography (CT) or magnetic resonance imaging (MRI) [12]. All laboratory analyses were performed at a central laboratory (Quintiles). Normal laboratory ranges used as reference limits when evaluating pancreatic enzymes were 13-53 U/L for pancreatic amylase, 20-112 U/L for total amylase and 0-60 U/L for lipase.

\section{Statistics}

This analysis was conducted on a safety population set (defined as all patients who received $\geq 1$ dose of dulaglutide $1.5 \mathrm{mg}$ ). The LS mean changes in pancreatic enzyme levels and accompanying 95\% CIs were calculated using a mixed model with repeated measures, where baseline enzyme level, subgroup factor, visit number and the interaction term between the subgroup factor and the visit number were treated as covariates and the patient was treated as a random effect. Categorical variables were summarized as counts and percentages and continuous variables were summarized using, mean (standard deviation [SD]). All analyses were performed using SAS Version 9.4.

\section{RESULTS}

\section{Patients}

A total of 203 Chinese patients who received dulaglutide $1.5 \mathrm{mg}$ for 26 weeks were included in this analysis. Patients had a mean age of $54.6 \pm 10.0$ years, $59.1 \%$ were male, the mean BMI was $25.9 \pm 3.2 \mathrm{~kg} / \mathrm{m}^{2}$, the mean body weight was $72.1 \pm 12.2 \mathrm{~kg}$, and the mean baseline triglyceride level was $2.2 \pm 1.8 \mathrm{mmol} / \mathrm{L}$ (Table 1). The mean duration of diabetes was $7.7 \pm 4.6$ years and at baseline the mean HbA1c was $8.4 \pm 1.2 \%$. Furthermore, the majority of patients were receiving metformin 
Table 1 Patient demographics and baseline characteristics

\begin{tabular}{lc}
\hline Variable $^{\mathrm{a}}$ & $\begin{array}{l}\text { Dulaglutide 1.5 mg } \\
(\boldsymbol{n}=\mathbf{2 0 3})\end{array}$ \\
\hline Age, years & $54.6(10.0)$ \\
Males, $n$ (\%) & $120(59.1)$ \\
Weight, kg & $72.1(12.2)$ \\
Body mass index, kg/m ${ }^{2}$ & $25.9(3.2)$ \\
Duration of diabetes, years & $7.7(4.6)$ \\
Baseline HbAlc, \% & $8.4(1.2)$ \\
Triglycerides, mmol/L & $2.2(1.8)$ \\
Pancreatic amylase, U/L & $25.3(10.8)$ \\
Total amylase, U/L & $57.0(18.9)$ \\
Lipase, U/L & $39.9(21.1)$ \\
Gall stones, $n$ (\%) & $0(0)$ \\
Concomitant OAMs, $n$ (\%) & \\
Metformin only & $87(42.9)$ \\
Metformin + sulfonylurea & $86(42.4)$ \\
Sulfonylurea only & $30(14.8)$ \\
\hline
\end{tabular}

$O A M s$ oral antihyperglycemic medications

${ }^{a}$ Values are mean $(\mathrm{SD})$ unless specified

monotherapy $(42.9 \%)$ or metformin plus sulfonylurea (42.4\%). At baseline, the mean levels of pancreatic amylase, total amylase and total lipase were $25.3 \pm 10.8 \mathrm{U} / \mathrm{L}, 57.0 \pm 18.9 \mathrm{U} / \mathrm{L}$, and $39.9 \pm 21.1 \mathrm{U} / \mathrm{L}$, respectively (Table 1 ).

\section{Pancreatic Safety}

Overall, a moderate and comparable increase in pancreatic amylase, total amylase and lipase levels within the normal range was observed between baseline and Week 26 in all patient subgroups (Table 2). No confirmed incidences of pancreatitis were reported by independent adjudication.

The LS mean increase in pancreatic amylase (U/L) from baseline to Week 26 was comparable across patients stratified by age $(<60$ years: 5.34 $[95 \%$ confidence interval [CI]: 3.35,
$7.32]) ; \geq 60$ years: $6.71[3.59,9.83]$ ), sex (female: 5.85 [3.28, 8.42]; male: 5.66 [3.44, 7.87]), duration of diabetes ( $<10$ years: 6.15 [4.13, 8.17]; $\geq 10$ years: 4.85 [1.81, 7.89]), baseline weight (<70 kg: 6.19 [3.67, 8.70]; $\geq 70 \mathrm{~kg}: 5.39$ $[3.14,7.64])$, baseline BMI $\left(<25 \mathrm{~kg} / \mathrm{m}^{2}: 5.92\right.$ [3.36, 8.49]; $\left.\geq 25 \mathrm{~kg} / \mathrm{m}^{2}: 5.61 \quad[3.40, \quad 7.82]\right)$, baseline HbA1c (<8.5\%: $6.82 \quad$ [4.67, 8.97]; $\geq 8.5 \%$ : $4.08 \quad[1.40,6.75])$, baseline triglycerides $\quad(<2.3 \mathrm{mmol} / \mathrm{L}: \quad 4.94 \quad[2.99$, $6.89] ; \geq 2.3 \mathrm{mmol} / \mathrm{L}: 8.04[4.74,11.33])$, and concomitant OAMs (metformin only: 5.68 $[3.10,8.26]$; sulfonylurea only: 5.44 [0.83, 10.06]; metformin plus sulfonylurea: 5.87 [3.37, 8.37]) (Fig. 1). P-values were $>0.05$ for all intrasubgroup differences.

Similar results were observed for the changes in total amylase (Fig. 2) and lipase (Fig. 3) between baseline and Week 26 .

\section{DISCUSSION}

To our knowledge, this post-hoc subgroup analysis of AWARD-CHN2 is the first analysis conducted in Chinese patients with T2DM to investigate the pancreatic safety of dulaglutide, or any GLP-1RA, stratified by influencing factors. The results demonstrated that once-weekly dulaglutide $1.5 \mathrm{mg}$ was associated with moderate increases in pancreatic enzyme levels within the normal range, with no events confirmed as pancreatitis by independent adjudication. Furthermore, comparable increases in pancreatic enzyme levels were observed between subgroups of patients stratified by key demographic characteristics and factors that may be associated with pancreatic safety including age, sex, duration of diabetes, weight, BMI, baseline HbA1c, baseline triglycerides, and concomitant OAM use. Together, these findings suggest that the clinical use of dulaglutide $1.5 \mathrm{mg}$ in Chinese patients is not associated with pancreatic safety issues.

The findings of our analysis are further supported by other recent evidence for the pancreatic safety of dulaglutide. Data from a pooled assessment of pancreatic safety from four Phase II and five Phase III trials reported a comparable exposure-adjusted incidence rate of acute 
Table 2 Mean pancreatic enzyme levels at baseline and Week 26 in Chinese patients with T2DM receiving dulaglutide $1.5 \mathrm{mg}$, stratified by potential influencing factors

\begin{tabular}{|c|c|c|c|c|c|c|c|}
\hline \multirow[t]{2}{*}{ Subgroup } & \multirow[t]{2}{*}{$n$} & \multicolumn{2}{|c|}{ Pancreatic amylase, $\mathrm{U} / \mathrm{L}$} & \multicolumn{2}{|c|}{ Total amylase, U/L } & \multicolumn{2}{|c|}{ Lipase, U/L } \\
\hline & & $\overline{\mathbf{B L}}$ & W26 & $\overline{\mathrm{BL}}$ & W26 & $\overline{\mathrm{BL}}$ & W26 \\
\hline \multicolumn{8}{|l|}{ Age } \\
\hline$<60$ years & 143 & 24.06 & 30.18 & 54.78 & 62.46 & 38.31 & 51.42 \\
\hline$\geq 60$ years & 60 & 28.23 & 34.23 & 62.18 & 69.40 & 43.63 & 52.77 \\
\hline \multicolumn{8}{|l|}{ Sex } \\
\hline Male & 120 & 25.63 & 31.77 & 57.35 & 64.66 & 40.18 & 52.42 \\
\hline Female & 83 & 24.81 & 30.78 & 56.42 & 64.19 & 39.46 & 51.00 \\
\hline \multicolumn{8}{|l|}{ Duration of diabetes } \\
\hline$<10$ years & 145 & 23.99 & 30.82 & 55.01 & 63.51 & 37.71 & 51.72 \\
\hline$\geq 10$ years & 58 & 28.55 & 32.53 & 61.86 & 66.56 & 45.31 & 52.00 \\
\hline \multicolumn{8}{|l|}{ Baseline weight } \\
\hline$<70 \mathrm{~kg}$ & 89 & 24.74 & 31.22 & 58.42 & 65.85 & 39.67 & 52.20 \\
\hline$\geq 70 \mathrm{~kg}$ & 114 & 25.73 & 31.45 & 55.84 & 63.33 & 40.04 & 51.50 \\
\hline \multicolumn{8}{|l|}{ Body mass index } \\
\hline$<25 \mathrm{~kg} / \mathrm{m}^{2}$ & 88 & 24.93 & 31.17 & 57.11 & 65.60 & 39.57 & 49.74 \\
\hline$\geq 25 \mathrm{~kg} / \mathrm{m}^{2}$ & 115 & 25.57 & 31.48 & 56.86 & 63.61 & 40.12 & 53.33 \\
\hline \multicolumn{8}{|l|}{ Baseline $\mathrm{HbAlc}$} \\
\hline$<8.5 \%$ & 123 & 26.21 & 32.83 & 58.02 & 66.63 & 40.27 & 54.86 \\
\hline$\geq 8.5 \%$ & 80 & 23.89 & 29.04 & 55.36 & 61.07 & 39.29 & 47.07 \\
\hline \multicolumn{8}{|l|}{ Baseline triglycerides } \\
\hline$<2.3 \mathrm{mmol} / \mathrm{L}$ & 149 & 26.38 & 31.40 & 57.54 & 64.18 & 41.01 & 51.04 \\
\hline$\geq 2.3 \mathrm{mmol} / \mathrm{L}$ & 54 & 22.31 & 31.19 & 55.41 & 65.25 & 36.78 & 53.98 \\
\hline \multicolumn{8}{|l|}{ Concomitant OAMs } \\
\hline Metformin only & 87 & 24.70 & 31.10 & 54.91 & 63.05 & 39.59 & 51.23 \\
\hline SU only & 30 & 25.10 & 30.71 & 56.47 & 63.92 & 39.83 & 49.29 \\
\hline Metformin $+S U$ & 86 & 25.97 & 31.76 & 59.23 & 65.92 & 40.20 & 53.07 \\
\hline
\end{tabular}

$B L$ baseline, $H b A 1 c$ glycated hemoglobin, $O A M$ oral antihyperglycemic medication, $S U$ sulfonylurea, W26 Week 26

pancreatitis for patients receiving dulaglutide versus placebo [30]. Our results are also supported by prior investigations of dulaglutide safety in Asian patients. In the Phase III AWARD-CHN1 trial, among a cohort of EastAsian patients with T2DM who received dulaglutide or glimepiride, no adjudicated cases of acute or chronic pancreatitis occurred and no patients experienced increases in pancreatic amylase or total amylase levels $>3$ times the ULN after 26 weeks [24]. Similarly, a pooled analysis of three Phase III studies of dulaglutide 


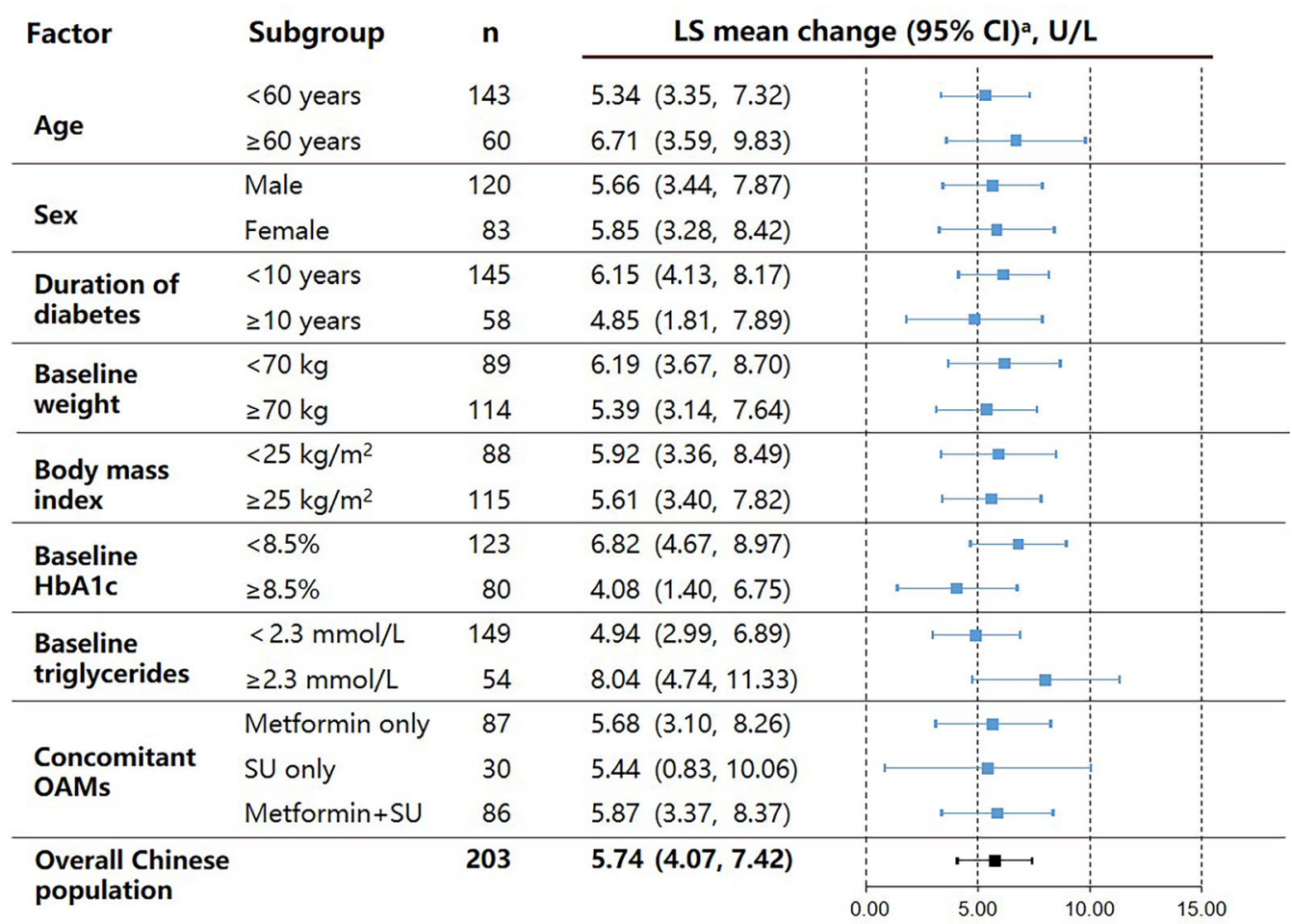

Fig. 1 Least squares mean change in pancreatic amylase level in Chinese patients with T2DM receiving dulaglutide $1.5 \mathrm{mg}$ from baseline to 26 weeks of treatment, stratified by potential influencing factors. ${ }^{2} \mathrm{LS}$ means and 95\% CIs within each patient subgroup were calculated using a

conducted in Japanese patients with T2DM reported increases from baseline amylase and lipase levels but a very low incidence of acute pancreatitis $(2 / 917$ patients, confirmed by independent adjudication) [31]. Finally, although our study does not report long-term safety data, evidence for the long-term safety of dulaglutide was provided by the Researching Cardiovascular Events with a Weekly Incretin in Diabetes (REWIND) study which demonstrated no significant difference in the incidence of adjudicated pancreatic adverse events between dulaglutide and placebo over a median followup of 5.4 years [32]. Although the above-mentioned studies and analyses have previously shown no association between dulaglutide use and pancreatic safety, most were conducted in predominantly Caucasian patients and there are known differences in the etiology, risk factors for, and incidence of pancreatitis between
MMRM model. All $p$ values were $>0.05$ for each subgroup comparison. CI confidence interval, $H b A l c$ glycated hemoglobin, $L S$ least squares, $M M R M$ mixedmodel repeated measures, $O A M$ oral antihyperglycemic medication, $S U$ sulfonylurea

patients of different racial and social backgrounds [29]. Furthermore, the present study builds on this previous research by conducting a deeper investigation of pancreatic safety grouped by known risk factors for pancreatitis. Given that China has an ageing population and that patients with T2DM have a high prevalence of obesity and hypertriglyceridemia, the present analysis would provide new and important information to inform clinical practice.

An aging population has contributed to the increased prevalence of total diabetes in China, with a current estimated prevalence of $20.2 \%$ in people aged $>60$ years [22]. Aging is also associated with many T2DM comorbidities including renal impairment and a high risk for adverse events such as recurring hypoglycemia. In addition, an appreciable increase in the incidence of, and risk of mortality from, acute pancreatitis has been observed among elderly 


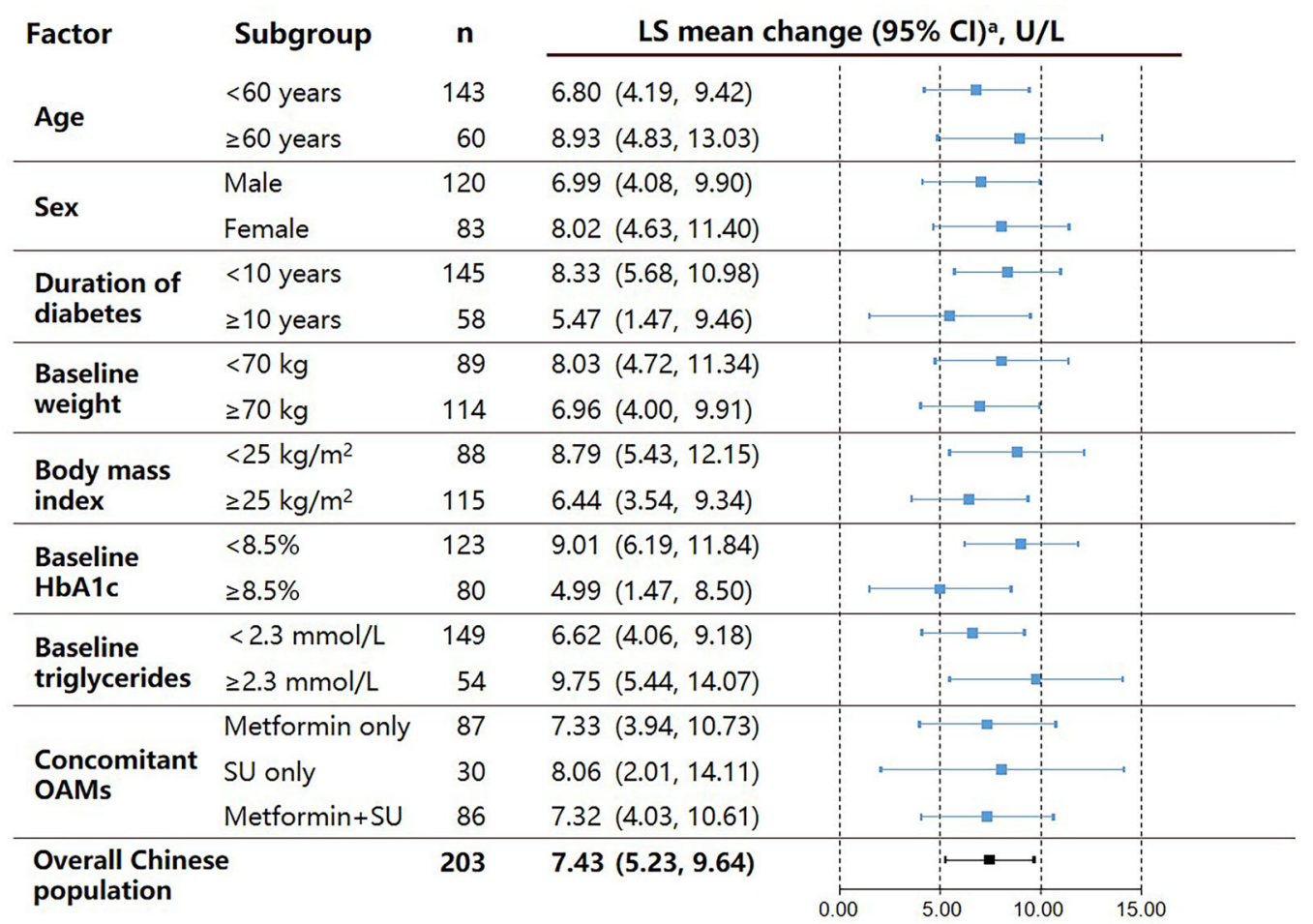

Fig. 2 Least squares mean change in total amylase level in Chinese patients with T2DM receiving dulaglutide $1.5 \mathrm{mg}$ from baseline to 26 weeks of treatment, stratified by potential influencing factors. ${ }^{a} \mathrm{LS}$ means and 95\% CIs within each patient subgroup were calculated using a

patients ( $>60$ years) [33]. Previous studies have shown that the efficacy and safety of dulaglutide is similar across patient age groups $[34,35]$. Furthermore, liraglutide and exenatide have been shown to be well tolerated regardless of patient age $[36,37]$. However, the safety outcomes reported by these prior studies mainly included hypoglycemia and gastrointestinal adverse events, and there are limited data on the pancreatic safety of GLP-1 RAs in elderly patients. The present study addresses this knowledge gap and provides evidence that the pancreatic safety profile of dulaglutide is similar in Chinese patients with T2DM aged $<60$ and $\geq 60$ years and, together with previous reports, suggests dulaglutide is a safe and effective treatment option for elderly patients with T2DM [34, 35]. The results of this analysis also showed no association between patient sex and pancreatic safety of dulaglutide.
MMRM model. All $p$ values were $>0.05$ for each subgroup comparison. $C I$ confidence interval, HbAlc glycated hemoglobin, $L S$ least squares, MMRM mixedmodel repeated measures, $O A M$ oral antihyperglycemic medication, $S U$ sulfonylurea

GLP-1 RAs improve glycemic control and promote weight loss [23], thus they are frequently prescribed to patients with T2DM who are overweight or obese $[38,39]$. However, obesity is known to increase the incidence and severity of acute pancreatitis [14], which makes it particularly important to investigate the pancreatic safety of GLP-1 RAs in overweight/ obese T2DM patients. The present study showed moderate elevations of amylase and lipase within a normal range in overweight and obese patients, which is in accordance with a previous study of liraglutide that reported asymptomatic elevations of amylase and lipase in overweight/ obese participants that did not predict subsequent development of acute pancreatitis [40]. The present study further demonstrated no association between bodyweight and pancreatic enzyme levels. Our data show no pancreatic safety concerns with dulaglutide treatment in 


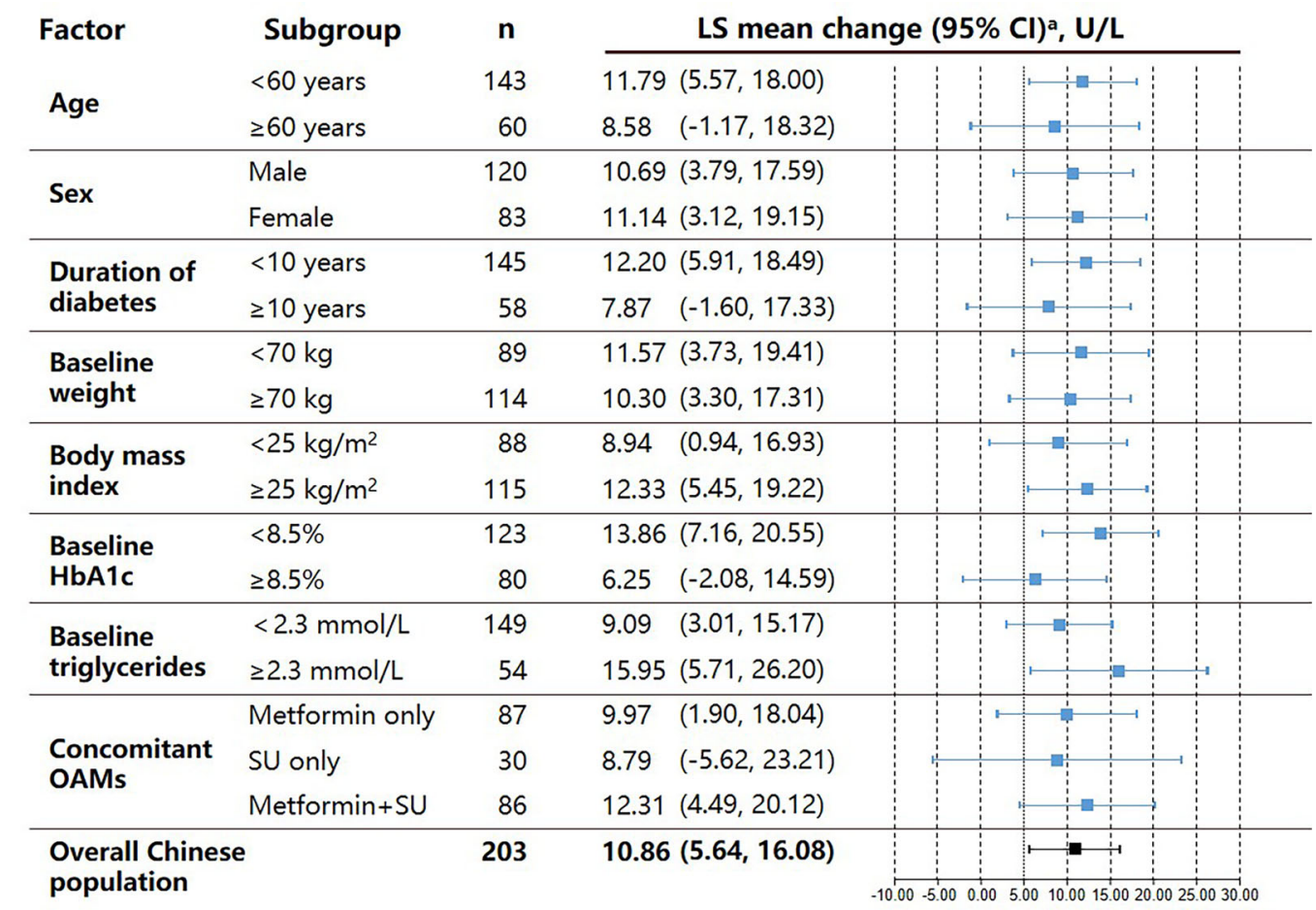

Fig. 3 Least squares mean change in lipase level in Chinese patients with T2DM receiving dulaglutide $1.5 \mathrm{mg}$ from baseline to 26 weeks of treatment, stratified by potential influencing factors. ${ }^{2} \mathrm{LS}$ means and $95 \% \mathrm{CIs}$ within each patient subgroup were calculated using a

Chinese patients with T2DM regardless of their baseline bodyweight or BMI.

Hypertriglyceridemia is another well-documented cause of acute pancreatitis [15-17], accounting for up to $9 \%$ of cases [41-44]. Both risk and severity of acute pancreatitis increase with increasing triglyceride levels [45]. Acute pancreatitis secondary to hyperlipidemia is characterized by several presentations, among which the most common is a patient with poorly controlled T2DM with a history of hypertriglyceridemia [46]. Therefore, evidence for the pancreatic safety of GLP-1 RAs in T2DM patients with hypertriglyceridemia is vital to support clinical decision making. A serum triglyceride level of $2.3-5.6 \mathrm{mmol} / \mathrm{L}$ is classified as "high triglycerides" and $\geq 5.6 \mathrm{mmol} / \mathrm{L}$ as "very high triglycerides" according to the NCEP ATP III criteria [28]. Based on these criteria, a triglyceride level of $2.3 \mathrm{mmol} / \mathrm{L}$ was selected as
MMRM model. All $p$ values were $>0.05$ for each subgroup comparison. CI confidence interval, HbAlc glycated hemoglobin, $L S$ least squares, $M M R M$ mixedmodel repeated measures, $O A M$ oral antihyperglycemic medication, $S U$ sulfonylurea

the cut-off for this analysis and dulaglutide demonstrated similar pancreatic safety irrespective of triglyceride level. Due to a limited number of patients with a serum triglyceride level $\geq 5.6 \mathrm{mmol} / \mathrm{L}$ (data not shown), we did not further stratify patients using this higher cut-off. Our results show that dulaglutide can be considered a safe treatment option for patients with T2DM and high triglycerides; however, the results should be cautiously interpreted for patients with serum triglyceride levels $\geq 5.6 \mathrm{mmol} / \mathrm{L}$.

In the clinical setting, dulaglutide is most frequently used in combination with concomitant OAMs, most commonly metformin and/or a sulphonylurea [47-49]. The evidence on the influence of OAM use on pancreatic safety is equivocal. Antonio et al. reported that longterm use of metformin was associated with a decreased risk of pancreatitis, while 
sulfonylureas seemed to increase the risk [50]. Blomgren et al. found that the sulfonylurea glyburide increased the risk of acute pancreatitis, but metformin did not reduce the risk [51]. Interestingly, Lai et al. reported that use of OAMs reduced the risk of acute pancreatitis among T2DM patients, particularly those taking metformin, sulfonylureas, thiazolidinediones, or $\alpha$-glucosidase inhibitors, and the risk was reduced as the number of drugs used increased [21]. Despite the confounding factors of concomitant OAMs, the results of the present study show similar changes in pancreatic enzyme levels for patients receiving concomitant sulphonylurea, metformin or both in combination. These findings show that dulaglutide is not associated with pancreatic safety concerns in patients receiving metformin and/or sulphonylurea.

While data suggest that T2DM is associated with an increased risk of acute pancreatitis and pancreatic cancer $[20,50]$, the increased incidence can be largely attributed to the higher prevalence of obesity and other T2DM-associated conditions such as cholelithiasis in this patient population [52]. Despite this, T2DMspecific characteristics have been investigated as risk factors for both acute pancreatitis and pancreatic cancer. For example, longer duration of T2DM has been associated with an increased risk of developing pancreatic cancer [53]. However, a study comparing 1426 patients with diabetes (90.9\% with T2DM) against matched individuals without diabetes from the same community found no association between duration of diabetes or HbA1c level and incidence of pancreatitis [52]. Similarly, the results of the present study found no association between increase in pancreatic enzyme levels and duration of T2DM or baseline HbA1c level among patients with T2DM receiving dulaglutide.

Limitations of this analysis include that it is a post hoc subgroup analysis of a larger study, with a population of over 203 Chinese patients, representing approximately $25 \%$ of the population of the original AWARD-CHN2 trial, and this may have limited the power of statistical testing [11]. However, despite the relatively small patient number, the present analysis represents one of the largest data sets collected on dulaglutide use in Chinese patients to date. Furthermore, no incidence of pancreatitis was observed among patients with T2DM receiving dulaglutide in the AWARD-CHN1 $(n=492)$ [24] or AWARD-CHN2 studies $(n=515)$ [11], giving data from a combined total of 1007 patients that support our findings. Another potential limitation is that patients with a history of pancreatitis were excluded from the AWARDCHN2 study which may have led to selection bias. In addition, pancreatic safety was not evaluated in patients with 'very high' triglyceride levels $(\geq 5.6 \mathrm{mmol} / \mathrm{L})$, which may limit the generalizability of the results to patients with extremely elevated triglyceride levels. Although our analysis did not include comparative pancreatic safety data from Chinese patients included in AWARD-CHN2 who received insulin glargine, there have been no previous reports of pancreatic safety events with insulin glargine and the pancreatic safety of insulin glargine was already described in the primary AWARD-CHN2 publication [11]. Finally, this analysis presents results through 26 weeks of treatment, which does not allow assessment of longer-term effects of dulaglutide on the pancreas.

\section{CONCLUSIONS}

In Chinese patients with T2DM treated with dulaglutide $1.5 \mathrm{mg}$ in the AWARD-CHN2 study, modest elevations in pancreatic enzymes within the normal range were observed between baseline and Week 26 and were not associated with clinically relevant pancreatitis events. Changes in pancreatic enzyme levels did not show any association with patient age, sex, duration of diabetes, baseline bodyweight, BMI, HbA1c, triglyceride level or use of concomitant OAMs. The results suggest that the clinical use of dulaglutide in Chinese patients is not associated with pancreatic safety issues. However, for safety reasons, GLP-1 RA treatment is not recommended for patients with suspected or diagnosed pancreatitis. 


\section{ACKNOWLEDGEMENTS}

Funding. This study and the journal's rapid service fee were funded by Eli Lilly and Company.

Authors' Contributions. Yan Zhou, Jiankun Zhu, Haiya $\mathrm{Wu}$, Yuying Deng and Qiuhe Ji all made substantial contributions to the study concept and design, acquisition of data, and analysis and interpretation of data, drafted the article and revised it critically for important intellectual content, gave final approval of the version to be published and agree to take responsibility for the integrity of the work as a whole in ensuring that questions related to the accuracy or integrity of any part of the work are appropriately investigated and resolved.

Authorship. All named authors meet the International Committee of Medical Journal Editors (ICMJE) criteria for authorship for this article, take responsibility for the integrity of the work as a whole, and have given their approval for this version to be published.

Medical Writing, Editorial, and Other Assistance. The authors wish to acknowledge Dr. Jake Burrell (PhD, Rude Health Consulting) for preparing the first draft and final revision. Support for this assistance was funded by Eli Lilly and Company. The authors also thank Chunli Shi (Eli Lilly and Company) and Dr Qiqi Zhang (PhD, Eli Lilly and Company) for review and critical suggestions for improvement. The authors are indebted to the patients/subjects who participated in this study, and their families. The authors are indebted to all of the physicians, nurses, and study coordinators who cared for the patients.

Disclosures. Yan Zhou has nothing to disclose. Jiankun Zhu, Haiya Wu and Yuying Deng are employees of Eli Lilly and Company. Haiya $\mathrm{Wu}$ and Yuying Deng hold equity in Eli Lilly and Company. Qiuhe Ji reports having received consulting fees and lecture fees from Eli Lilly and Company, Novo Nordisk, Merck Sharp \& Dohme China, Sanofi Aventis, Huadong
Pharmaceuticals Company, and Medtronic, and received authoring support from Eli Lilly and Company.

Compliance with Ethics Guidelines. The study protocol received approval from the ethics review board at each study center including the master ethics review board at Ruijin Hospital Affiliated to Shanghai Jiao Tong University. The study was conducted in-line with the ethical principles outlined in the Declaration of Helsinki and local regulations, and all patients provided written informed consent before randomization. A full list of the Institutional Review Boards that approved this study can be found in the Supplementary Material.

Data Availability. The datasets generated during and/or analyzed during the current study are available from the corresponding author on reasonable request.

Open Access. This article is licensed under a Creative Commons Attribution-NonCommercial 4.0 International License, which permits any non-commercial use, sharing, adaptation, distribution and reproduction in any medium or format, as long as you give appropriate credit to the original author(s) and the source, provide a link to the Creative Commons licence, and indicate if changes were made. The images or other third party material in this article are included in the article's Creative Commons licence, unless indicated otherwise in a credit line to the material. If material is not included in the article's Creative Commons licence and your intended use is not permitted by statutory regulation or exceeds the permitted use, you will need to obtain permission directly from the copyright holder. To view a copy of this licence, visit http://creativecommons.org/licenses/by$\mathrm{nc} / 4.0 /$.

\section{REFERENCES}

1. Taylor R. Type 2 diabetes: etiology and reversibility. Diabetes Care. 2013;36(4):1047-55. 
2. Li Y, Teng D, Shi X, Qin G, Qin Y, Quan H, et al. Prevalence of diabetes recorded in mainland China using 2018 diagnostic criteria from the American Diabetes Association: national cross sectional study. BMJ (Clinical research). 2020;369:997.

3. Htike ZZ, Zaccardi F, Papamargaritis D, Webb DR, Khunti K, Davies MJ. Efficacy and safety of glucagon-like peptide- 1 receptor agonists in type 2 diabetes: A systematic review and mixed-treatment comparison analysis. Diabetes Obes Metab. 2017;19(4):524-36.

4. Denker PS, Dimarco PE. Exenatide (exendin-4)-induced pancreatitis: a case report. Diabetes Care. 2006;29(2):471.

5. Elashoff M, Matveyenko AV, Gier B, Elashoff R, Butler PC. Pancreatitis, pancreatic, and thyroid cancer with glucagon-like peptide-1-based therapies. Gastroenterology. 2011;141(1):150-6.

6. Singh S, Chang HY, Richards TM, Weiner JP, Clark JM, Segal JB. Glucagonlike peptide 1-based therapies and risk of hospitalization for acute pancreatitis in type 2 diabetes mellitus: a population-based matched case-control study. JAMA Intern Med. 2013;173(7):534-9.

7. Monami M, Nreu B, Scatena A, Cresci B, Andreozzi $F$, Sesti G, et al. Safety issues with glucagon-like peptide-1 receptor agonists (pancreatitis, pancreatic cancer and cholelithiasis): Data from randomized controlled trials. Diabetes Obes Metab. 2017;19(9): 1233-41.

8. Kristensen SL, Rørth R, Jhund PS, Docherty KF, Sattar N, Preiss D, et al. Cardiovascular, mortality, and kidney outcomes with GLP-1 receptor agonists in patients with type 2 diabetes: a systematic review and meta-analysis of cardiovascular outcome trials. Lancet Diabetes Endocrinol. 2019;7(10):776-85.

9. Egan AG, Blind E, Dunder K, de Graeff PA, Hummer BT, Bourcier T, et al. Pancreatic safety of incretinbased drugs-FDA and EMA assessment. N Engl J Med. 2014;370(9):794-7.

10. Scott LJ. Dulaglutide: a review in type 2 diabetes. Drugs. 2020;80(2):197-208.

11. Wang W, Nevárez L, Filippova E, Song KH, Tao B, $\mathrm{Gu} \mathrm{L}$, et al. Efficacy and safety of once-weekly dulaglutide versus insulin glargine in mainly Asian patients with type 2 diabetes mellitus on metformin and/or a sulphonylurea: a 52-week open-label, randomized phase III trial. Diabetes Obes Metab. 2019;21(2):234-43.

12. Lankisch PG, Apte M, Banks PA. Acute pancreatitis. Lancet (London, England). 2015;386(9988):85-96.
13. Tenner S, Baillie J, DeWitt J, Vege SS. American College of Gastroenterology guideline: management of acute pancreatitis. Am J Gastroenterol. 2013;108(9):1400-15.

14. Khatua B, El-Kurdi B, Singh VP. Obesity and pancreatitis. Curr Opin Gastroenterol. 2017;33(5): 374-82.

15. Berglund L, Brunzell JD, Goldberg AC, Goldberg IJ, Sacks F, Murad MH, et al. Evaluation and treatment of hypertriglyceridemia: an Endocrine Society clinical practice guideline. J Clin Endocrinol Metab. 2012;97(9):2969-89.

16. Hansen SEJ, Madsen CM, Varbo A, Nordestgaard BG. Body mass index, triglycerides, and risk of acute pancreatitis: a population-based study of 118000 individuals. J Clin Endocrinol Metab. 2020;105(1): 163-74.

17. Yuan G, Al-Shali KZ, Hegele RA. Hypertriglyceridemia: its etiology, effects and treatment. CMAJ Can Med Assoc J J de l'Assoc Med Can. 2007;176(8): 1113-20.

18. Gloor B, Ahmed Z, Uhl W, Büchler MW. Pancreatic disease in the elderly. Best Pract Res Clin Gastroenterol. 2002;16(1):159-70.

19. Koziel D, Gluszek-Osuch M, Suliga E, Zak M, Gluszek S. Elderly persons with acute pancreatitis specifics of the clinical course of the disease. Clin Interv Aging. 2019;14:33-41.

20. Girman CJ, Kou TD, Cai B, Alexander CM, O’Neill EA, Williams-Herman DE, et al. Patients with type 2 diabetes mellitus have higher risk for acute pancreatitis compared with those without diabetes. Diabetes Obes Metab. 2010;12(9):766-71.

21. Lai SW, Muo CH, Liao KF, Sung FC, Chen PC. Risk of acute pancreatitis in type 2 diabetes and risk reduction on anti-diabetic drugs: a populationbased cohort study in Taiwan. Am J Gastroenterol. 2011;106(9):1697-704.

22. Wang L, Gao P, Zhang M, Huang Z, Zhang D, Deng $\mathrm{Q}$, et al. Prevalence and ethnic pattern of diabetes and prediabetes in China in 2013. JAMA. $2017 ; 317(24): 2515-23$.

23. Brown E, Cuthbertson DJ, Wilding JP. Newer GLP-1 receptor agonists and obesity-diabetes. Peptides. 2018;100:61-7.

24. Chen YH, Huang CN, Cho YM, Li P, Gu L, Wang F, et al. Efficacy and safety of dulaglutide monotherapy compared with glimepiride in East-Asian patients with type 2 diabetes in a multicentre, double-blind, randomized, parallel-arm, active 
comparator, phase III trial. Diabetes Obes Metab. 2018;20(9):2121-30.

25. Yu M, Yuan GY, Zhang B, Wu HY, Lv XF. Efficacy and safety of dulaglutide by baseline HbA1c in Chinese patients with Type 2 diabetes: a post hoc analysis. Diabetes Ther Res Treat Educ Diabetes Relat Disord. 2020;11(5):1147-59.

26. Yu Pan C, Han P, Liu X, Yan S, Feng P, Zhou Z, et al. Lixisenatide treatment improves glycaemic control in Asian patients with type 2 diabetes mellitus inadequately controlled on metformin with or without sulfonylurea: a randomized, double-blind, placebo-controlled, 24-week trial (GetGoal-M-Asia). Diabetes Metab Res Rev. 2014;30(8):726-35.

27. Li Y, Li L, De Peng Y, Song GY, Ye SD, Du LY, et al. Efficacy and safety of dulaglutide versus insulin glargine in Chinese T2DM patients: a subgroup analysis of a randomized trial (AWARD-CHN2). Diabetes Ther Res Treat Educ Diab Relat Dis. 2019;10(4):1435-52.

28. Third Report of the National Cholesterol Education Program (NCEP) expert panel on detection, evaluation, and treatment of high blood cholesterol in adults (Adult Treatment Panel III) final report. Circulation. 2002;106(25):3143-421.

29. Yadav D, Lowenfels AB. The epidemiology of pancreatitis and pancreatic cancer. Gastroenterology. 2013;144(6):1252-61.

30. Nauck MA, Frossard JL, Barkin JS, Anglin G, Hensley IE, Harper KD, et al. Assessment of pancreas safety in the development program of once-weekly GLP-1 receptor agonist dulaglutide. Diabetes Care. 2017;40(5):647-54.

31. Emoto M, Oura T, Matsui A, Kazama H, Iwamoto N. Pancreatic safety in Japanese patients with type diabetes treated with once weekly dulaglutide 0 . $75 \mathrm{mg}$ up to 52 weeks in phase 3 clinical trials. Endocr J. 2017;64(2):191-206.

32. Gerstein HC, Colhoun HM, Dagenais GR, Diaz R, Lakshmanan M, Pais P, et al. Dulaglutide and cardiovascular outcomes in type 2 diabetes (REWIND): a double-blind, randomised placebo-controlled trial. Lancet (Lond, Engl). 2019;394(10193):121-30.

33. Yadav D, Lowenfels AB. Trends in the epidemiology of the first attack of acute pancreatitis: a systematic review. Pancreas. 2006;33(4):323-30.

34. Boustani MA, Pittman IT, Yuxvcs M, Thieu VT, Varnado OJ, Juneja R. Similar efficacy and safety of once-weekly dulaglutide in patients with type diabetes aged $\geq 65$ and $<65$ years. Diabetes Obes Metab. 2016;18(8):820-8.
35. Kuang J, Zhu J, Liu S, Li Q. Efficacy and safety of once-weekly dulaglutide in elderly chinese patients with Type 2 diabetes: a post hoc analysis of AWARD-CHN studies. Diabetes Ther Res Treat Educ Diabetes Relat Disord. 2020;11(10):2329-39.

36. Bode BW, Brett J, Falahati A, Pratley RE. Comparison of the efficacy and tolerability profile of liraglutide, a once-daily human GLP-1 analog, in patients with type 2 diabetes $\geq 65$ and $<65$ years of age: a pooled analysis from phase III studies. Am J Geriatr Pharmacother. 2011;9(6):423-33.

37. Pencek R, Blickensderfer A, Li Y, Brunell SC, Chen S. Exenatide once weekly for the treatment of type 2 diabetes: effectiveness and tolerability in patient subpopulations. Int J Clin Pract. 2012;66(11): 1021-32.

38. Carls GS, Tan R, Zhu JY, Tuttle E, Yee J, Edelman SV, et al. Real-world weight change among patients treated with glucagon-like peptide- 1 receptor agonist, dipeptidyl peptidase- 4 inhibitor and sulfonylureas for type 2 diabetes and the influence of medication adherence. Obes Sci Pract. 2017;3(3): 342-51.

39. Conget I, Mauricio D, Ortega R, Detournay B. Characteristics of patients with type 2 diabetes mellitus newly treated with GLP-1 receptor agonists (CHADIG Study): a cross-sectional multicentre study in Spain. BMJ Open. 2016;6(7):e010197.

40. Steinberg WM, Rosenstock J, Wadden TA, Donsmark M, Jensen CB, DeVries JH. Impact of liraglutide on amylase, lipase, and acute pancreatitis in participants with overweight/obesity and normoglycemia, prediabetes, or type 2 diabetes: secondary analyses of pooled data from the SCALE clinical development program. Diabetes Care. 2017;40(7): 839-48.

41. Párniczky A, Kui B, Szentesi A, Balázs A, Szücs Á, Mosztbacher D, et al. Prospective, multicentre, nationwide clinical data from 600 cases of acute pancreatitis. PLoS ONE. 2016;11(10):e0165309.

42. Zhu Y, Pan X, Zeng H, He W, Xia L, Liu P, et al. A study on the etiology, severity, and mortality of 3260 patients with acute pancreatitis according to the revised atlanta classification in jiangxi, china over an 8-year period. Pancreas. 2017;46(4):504-9.

43. Roberts SE, Akbari A, Thorne K, Atkinson M, Evans PA. The incidence of acute pancreatitis: impact of social deprivation, alcohol consumption, seasonal and demographic factors. Aliment Pharmacol Ther. 2013;38(5):539-48.

44. Carr RA, Rejowski BJ, Cote GA, Pitt HA, Zyromski NJ. Systematic review of hypertriglyceridemia-induced acute pancreatitis: a more virulent etiology? 
Pancreatol Off J Int Assoc Pancreatol (IAP). 2016;16(4):469-76.

45. Garg R, Rustagi T. Management of hypertriglyceridemia induced acute pancreatitis. Biomed Res Int. 2018;2018:4721357.

46. Fortson MR, Freedman SN, Webster PD 3rd. Clinical assessment of hyperlipidemic pancreatitis. Am J Gastroenterol. 1995;90(12):2134-9.

47. Boye KS, Sapin H, García-Pérez LE, Rosilio M, Orsini Federici M, Heitmann E, et al. The real-world observational prospective study of health outcomes with dulaglutide and liraglutide in type 2 diabetes patients (TROPHIES): baseline patient-reported outcomes. Diabetes Ther Res Treat Educ Diabetes Relat Disord. 2020;11(10):2383-99.

48. Mody R, Huang Q, Yu M, Zhao R, Patel H, Grabner $\mathrm{M}$, et al. Adherence, persistence, glycaemic control and costs among patients with type 2 diabetes initiating dulaglutide compared with liraglutide or exenatide once weekly at 12 -month follow-up in a real-world setting in the United States. Diabetes Obes Metab. 2019;21(4):920-9.
49. Yoo JH, Cho YK, Lee J, Kim HS, Kang YM, Jung CH, et al. Clinical efficacy and parameters affecting the response to dulaglutide treatment in patients with type 2 diabetes: a retrospective, real-world data study. Diabetes Ther Res Treat Educ Diabetes Relat Disord. 2019;10(4):1453-63.

50. Gonzalez-Perez A, Schlienger RG, Rodríguez LA. Acute pancreatitis in association with type 2 diabetes and antidiabetic drugs: a population-based cohort study. Diabetes Care. 2010;33(12):2580-5.

51. Blomgren KB, Sundström A, Steineck G, Wiholm BE. Obesity and treatment of diabetes with glyburide may both be risk factors for acute pancreatitis. Diabetes Care. 2002;25(2):298-302.

52. Davis TM, Drinkwater J, Davis WA. Incidence and precipitants of hospitalization for pancreatitis in people with diabetes: the Fremantle Diabetes Study. Diabetic Med J Br Diabet Assoc. 2014;31(8):913-9.

53. Brodovicz KG, Kou TD, Alexander CM, O'Neill EA, Engel SS, Girman CJ, et al. Impact of diabetes duration and chronic pancreatitis on the association between type 2 diabetes and pancreatic cancer risk. Diabetes Obes Metab. 2012;14(12):1123-8. 